\title{
Reprogrammed viruses as cancer therapeutics: targeted, armed and shielded
}

Roberto Cattaneo*, Tanner Miest* , Elena V. Shashkova ${ }^{\ddagger}$ and Michael A. Barry ${ }^{\ddagger}$

Abstract | Virotherapy is currently undergoing a renaissance, based on our improved understanding of virus biology and genetics and our better knowledge of many different types of cancer. Viruses can be reprogrammed into oncolytic vectors by combining three types of modification: targeting, arming and shielding. Targeting introduces multiple layers of cancer specificity and improves safety and efficacy; arming occurs through the expression of prodrug convertases and cytokines; and coating with polymers and the sequential usage of different envelopes or capsids provides shielding from the host immune response. Virus-based therapeutics are beginning to find their place in cancer clinical practice, in combination with chemotherapy and radiation.

When viruses were first recognized more than 100 years ago, the idea of using them to fight cancer, and in particular leukaemia, was considered ${ }^{1}$. Clinical reports of cancer regressions that were coincidental with natural virus infections continued through the first half of the twentieth century ${ }^{2,3}$. Based on these anecdotal observations, early clinical trials were performed in which bodily fluids that contained human or animal viruses were used to transmit infections to patients with cancer ${ }^{4}$. Often, the host immune response prevailed, but occasionally, in immunosuppressed patients, the infection persisted and the cancer regressed, although the morbidity that occurred as a result of the infection of normal tissues was unacceptable. Some of the clinical studies performed at that time seem alarming in the context of current ethical standards; however, these were desperate times for those afflicted with cancer ${ }^{3}$.

The advent of tissue culture in the 1950s and 1960s allowed viruses to be propagated in a more defined environment and cancers to be modelled by implanting cancer cells into rodents, which allowed pre-clinical experimentation with many types of human and animal viruses $^{5-10}$. The opportunity to influence the evolution of viruses by adapting them to grow well only in specific cancer cells and then using them as therapy for equivalent cancers was promptly recognized and seized ${ }^{11-13}$, but success was again limited, and research activity in the field of oncolytic virotherapy diminished because alternative approaches to improve efficacy were not available.
At this crossroads, oncolytic virotherapy was limited by the lack of knowledge of the determinants of viral tropism and of ways to manipulate those determinants to generate viruses that were more specific for cancer cells. It was recognized that cancer cells were better environments for the replication of naturally oncolytic viruses, whereas non-transformed cells could control virus infections. The need to improve the characteristics of natural oncolytic viruses became clear as more extensive testing identified limited efficacy or dose-limiting toxicities ${ }^{3,14}$. Consequently, research moved towards reprogramming viruses to become increasingly cancer specific, and thus safer. However, progress was initially slow, because an understanding of the natural virus tropism determinants and the molecular environment of the target cancer cells had to be developed.

During the past 20 years, tropism determinants have been identified and characterized for many different virus families. In addition, we can now easily visualize and quantify viral spread using reporter genes $^{15,16}$, and document how virus replication relates to therapeutic efficacy ${ }^{17}$. Most importantly, reversegenetics systems have been developed for almost every virus family, allowing the generation of viruses with improved oncolytic properties. Finally, our understanding of cancer has also improved with the availability of diagnostic markers and sophisticated animal models. These advances allow researchers to generate viruses with various levels of specificity for the molecular eccentricities of cancer cells. 


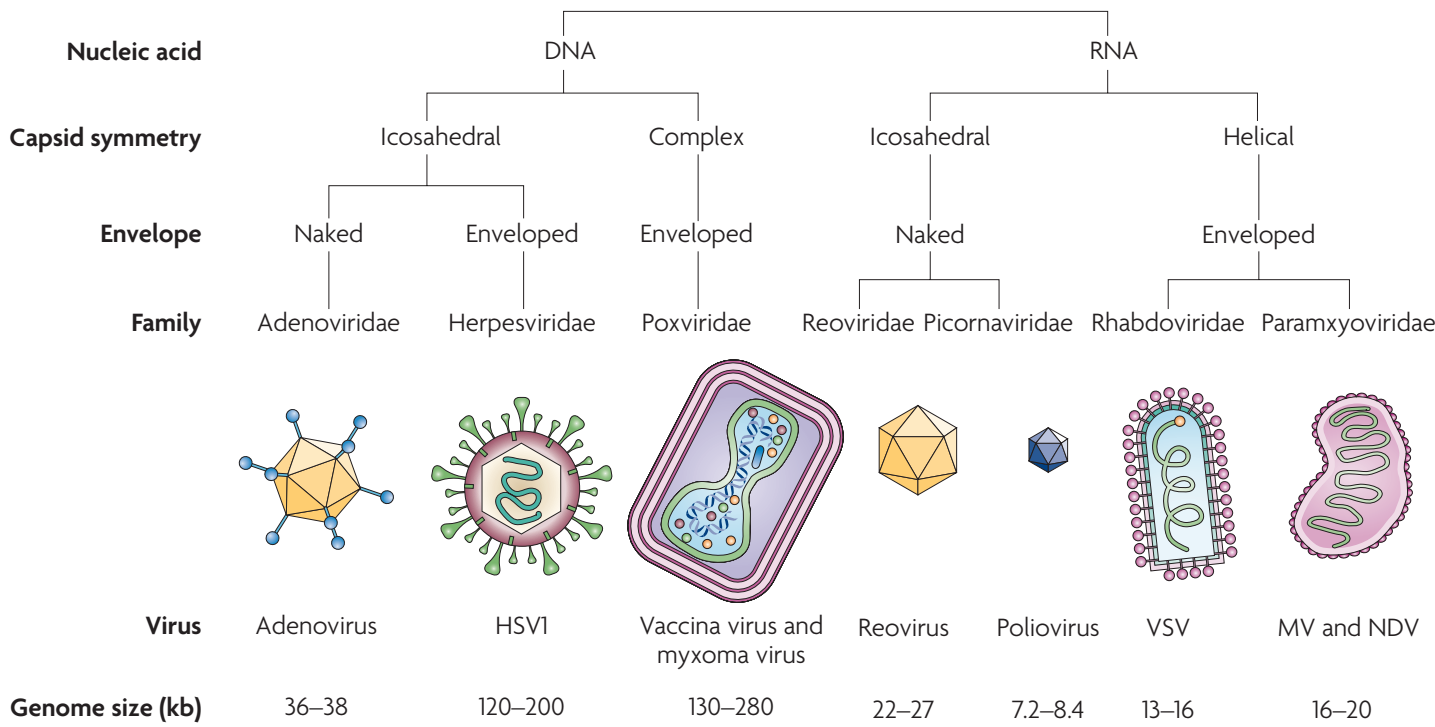

Figure 1 | Oncolytic viruses that are currently used in cancer clinical trials. The major characteristics of seven families of oncolytic viruses are summarized. Recombinant strains of all the DNA viruses shown are currently in clinical trials, whereas among the RNA viruses shown, only recombinant $\mathrm{MV}$ is in clinical trials; recombinant poliovirus and VSV are in pre-clinical trials and non-engineered strains of reovirus and NDV are in Phase I-II clinical trials. HSV1, herpes simplex virus 1; MV, measles virus; NDV, Newcastle disease virus; VSV, vesicular stomatitis virus.

FIGURE 1 and TABLE 1 introduce the most relevant families of human DNA and RNA viruses that are currently used in, or are approaching, clinical trials. Recombinant DNA viruses in clinical trials include adenovirus (Ad), herpes simplex virus 1 (HSV1) and vaccinia virus. Other DNA viruses that are approaching clinical trials include myxoma virus. The only engineered oncolytic RNA virus that is currently in clinical trials is measles virus (MV); non-engineered strains of Newcastle disease virus (NDV) and reovirus are currently in Phase I-II clinical trials, and reprogrammed poliovirus and vesicular stomatitis virus (VSV) are in pre-clinical trials. As the major clinical trials of oncolytic viruses for cancer therapy have recently been reviewed ${ }^{18}$, we will focus here mainly on the vector developments that are preparing viruses for the next generation of trials. The first half of this Review will discuss the principles of retargeting viruses to cancer cells, which are primarily illustrated using an RNA virus, $\mathrm{MV}$, and a DNA virus, Ad. The focus is exclusively on the genetic reprogramming of replicating viral vectors. The second half of this Review focuses on arming viruses and shielding them from the host immune response to improve oncolytic efficacy. We also address the clinical use of reprogrammed viruses in combination with chemotherapy and radiation, and discuss a five-step plan for reprogramming viruses into cancer therapeutics.

The most common and aggressive type of primary brain tumour. Treatment can involve chemotherapy, radiotherapy and surgery, none of which provide a cure

Matrix metalloproteinase A proteolytic enzyme that degrades the extracellular matrix and has important roles in tissue remodelling and tumour metastasis.

\section{Retargeting viral tropism}

When considering the development of an oncolytic agent for a tumour that is derived from a specific cell type, two general strategies can be used. First, viruses with a natural tropism for that cell type can be considered. This principle is illustrated by the selection of HSV to treat glioblastoma. The goal then becomes to deprogramme the virus from harming normal neurons, while maintaining oncolytic efficacy. Alternatively, one can reprogramme a virus that has only a marginal tropism for the target cell type. This strategy benefits from the inherently low toxicity of the virus for normal cells, but demands precise insights into the host mechanisms that limit viral spread and the availability of targeting elements to overcome these limitations. The success of both approaches is dependent on the selectivity of the strategies that are used. In this section, we discuss four complementary classes of targeting modifications, as illustrated in FIG. 2: particle activation, which is dependent on cancer-specific proteases; entry through cancer-specific cell-surface molecules; control of viral transcription and replication by tissue-specific promoters; and the preferential spread of viruses that exploit cancer-specific molecular defects.

We have selected the enveloped RNA virus MV (FIG. 3) and the icosahedral DNA virus Ad (FIG. 4) to illustrate how these alterations can be applied to viruses with different biological characteristics.

Activation through cancer-specific proteases. The replication and pathogenesis of almost every virus is dependent on interactions with host cell proteases. Importantly, enveloped viruses, such as paramyxoviruses, influenza and $\mathrm{HIV}-1$, require protease cleavage of viral glycoproteins for productive cell entry following receptor recognition ${ }^{19}$. Many cancer cells express proteases that could be exploited to enhance virus specificity. Desirable protease targets for oncolytic viruses that can be activated are those that are expressed preferentially and/or at high levels by cancer cells. Notably, matrix metalloproteinases (MMPs) are endopeptidases that are over-expressed in nearly every human cancer ${ }^{20}$.

Proof of principle for MMP protease activation was achieved using retroviruses by adding blocking ligands 


\begin{tabular}{|c|c|}
\hline Virus (strain and modifications) & Tumour target (clinical phase and application) \\
\hline Adenovirus 5 (dl1520 derivative) & $\begin{array}{l}\text { Squamous cell carcinoma of head and neck (approved } \\
\text { drug in China; intratumoural) }\end{array}$ \\
\hline Adenovirus 5 (PSE-E1A and E3 deleted) & Prostate (I; prostatic) \\
\hline Herpes simplex virus 1 (ICP34.5 defective) & Glioblastoma multiforme (II; intratumoural) \\
\hline $\begin{array}{l}\text { Vaccinia virus (thymidine kinase knockout and expressing } \\
\text { granulocyte-macrophage colony-stimulating factor) }\end{array}$ & Advanced liver tumours (I-II; intratumoural) \\
\hline Reovirus (reolysin) & Superficial tumours (I; intralesional) \\
\hline Newcastle disease virus (PV701) & $\begin{array}{l}\text { Bladder, squamous cell carcinoma of head and neck and } \\
\text { ovarian (I-II; intravenous) }\end{array}$ \\
\hline $\begin{array}{l}\text { Measles virus ( } V \text { protein knockout and expressing the } \\
\text { reporter carcinoembryonic antigen or the effector sodium } \\
\text { iodide symporter) }\end{array}$ & $\begin{array}{l}\text { Ovarian (I; intratumoural), glioma (I-II; intratumoural) } \\
\text { and myeloma (I; intravenous) }\end{array}$ \\
\hline
\end{tabular}

that contained MMP-cleavable linkers to the amino (N) terminus of retroviral glycoproteins ${ }^{21,22}$. In another approach that introduced only minimal structural modifications, the protease cleavage specificity of the fusion protein from MV and Sendai virus was changed from being dependent on the ubiquitous protease furin or the respiratory airway protease tryptase Clara, respectively, to being dependent on an MMP23,24 (FIG. 3a). Recombinant $\mathrm{MV}$ that expressed the modified fusion protein (MVMMP) was unable to propagate or produce a cytopathic effect unless it was added to cells that expressed an MMP. In mice, MV-MMP retained full oncolytic activity when inoculated into MMP-positive subcutaneous cancers but, unlike wild-type MV, MV-MMP did not infect and kill susceptible mice after intracranial inoculation, which proved that the safety of the virus had been enhanced ${ }^{24}$.

These experiments illustrate the potential safety and efficacy benefits of retargeting oncolytic viruses to MMP-positive cancer cells at the level of virus particle activation. Another protease that can be targeted and that is secreted by invasive metastatic cancer cells is the urokinase-type plasminogen activator ${ }^{25}$. This retargeting strategy could be directly adapted to restrict cellular entry of other enveloped viruses that are currently being used in clinical trials, and which have fusion proteins that are dependent on protease activation, including HSV and other large DNA viruses and NDV among the paramyxoviruses. Additionally, it might be possible to modify the regulatory or structural proteins of viruses that have an icosahedral capsid to be dependent on proteases that are expressed preferentially and/or at high levels by cancer cells.

Fibre protein

In adenoviruses, a trimeric antennae-like protein that projects from the virion and mediates initial cell-binding events by different serotypes with CAR, CD46 and, perhaps, other receptors.

\section{Penton base}

The pentameric protein base of the fibre trimer. For some adenoviruses, this protein mediates interactions with cellular integrins for binding and cell entry. particle assembly ${ }^{27}$. In addition, the biological characteristics of ligands and viruses can sometimes be incompatible, making it difficult to combine certain ligands with some viruses.

Usually, only one viral protein is involved in receptor binding, but other proteins support subsequent particle internalization or membrane fusion. This is true for nonenveloped viruses, such as Ad, which uses its fibre protein for cell binding and its penton base for cell entry (FIG. 4). The substantial efforts to retarget Ad have recently been reviewed ${ }^{27}$, and therefore we will focus instead on targeting strategies for MV as an archetypical enveloped oncolytic virus. Among enveloped viruses, receptor targeting is most advanced in the Paramyxoviridae, in which two different glycoproteins - haemagglutinin and the fusion protein - carry out receptor binding and membrane fusion, respectively ${ }^{28,29}$. FIGURE 3 illustrates the structure of an MV particle and the modifications to haemagglutinin that are necessary to achieve retargeting.

To retarget viral tropism at the level of receptor recognition, virus entry through a natural receptor (or receptors) must first be inactivated. The primary receptor for wild-type MV is the signalling lymphocytic activation molecule (SLAM; also known as CD150) ${ }^{30}$, but the $\mathrm{MV}$ vaccine strain also binds to the ubiquitous CD46 (also known as membrane cofactor protein (MCP) $)^{31,32}$. To identify the residues of MV haemagglutinin that selectively support SLAM- or CD46-dependent cell entry, an iterative mutagenesis strategy and functional receptor-dependent fusion assays were used. This identified several residues that are required for either SLAM- or CD46-dependent fusion ${ }^{33}$ (FIG. 3b). Recombinant viruses with mutations in these residues were obtained by reverse genetics and shown to be selectively receptor blind, recognizing either CD46 or SLAM ${ }^{33}$.

The next retargeting step requires that viral tropism be expanded to target receptor proteins that are expressed preferentially on cancer cells. Proof of principle for this step was achieved by displaying the small specificity domains epidermal growth factor (EGF) or insulin-like growth factor 1 (IGF1) on MV haemagglutinin. When these domains were added to the extracellular terminus of haemagglutinin ${ }^{34}$, recombinant viruses that expressed these extended proteins became 
a Protease-dependent activation

Cancer cells

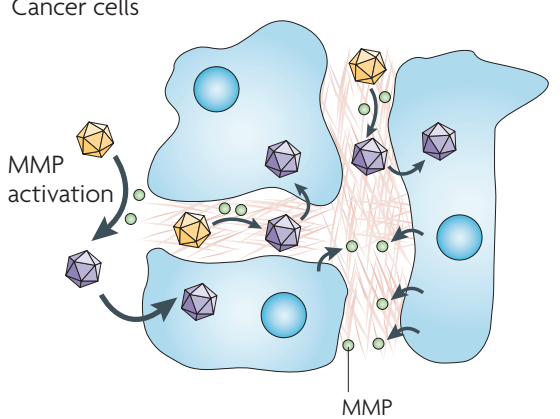

Normal cells

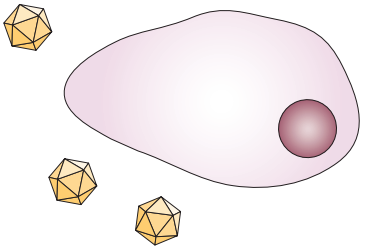
transcription

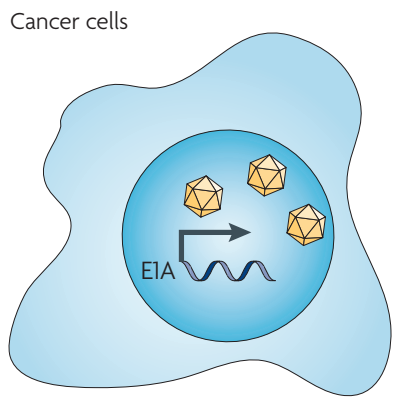

Normal cells

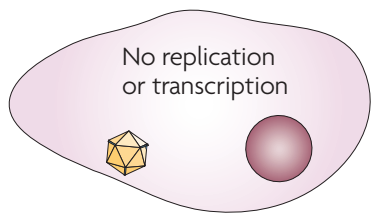

C Control of virus replication and b Cancer-cell-specific entry
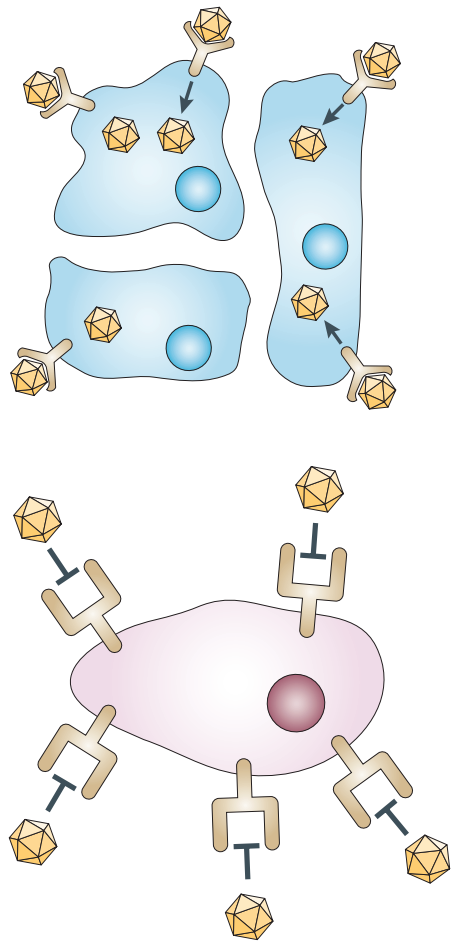

d Preferential spread

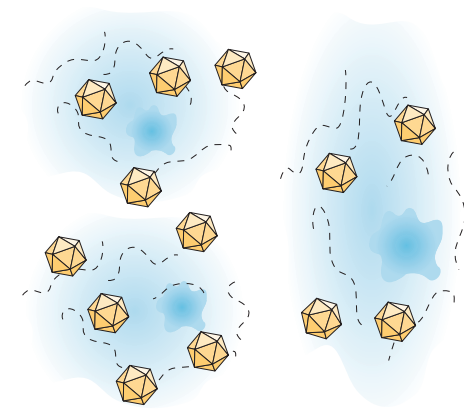

Figure 2 | Four layers of specificity for retargeting viral tropism. a | Virus particle activation can be reprogrammed to depend on proteases that are secreted by cancer cells. Activation occurs through matrix metalloproteases (MMPs) that are located in the tumour matrix. b | Recombinant viruses can be engineered to enter cells through a designated receptor rather than through the natural attachment protein. c | Viral transcription and replication can be made dependent on tissue- or cancer-specific promoters. $\mathbf{d}$ |Viruses with modifications or deletions of their immune-evasion proteins replicate preferentially in certain transformed cells. Not every targeting strategy can be applied to every virus, but more and more viruses with combined layers of specificity are being engineered for specific clinical trials. replication competent in previously non-susceptible cells that expressed the EGF or IGF1 receptors.

The applicability of receptor targeting has been greatly expanded by using domains that confer antibody-like specificity. In practice, however, antibodies are difficult to engineer into viral proteins, as they are tetrameric, contain disulphide bonds and are usually substantially larger than the viral proteins to be modified. Researchers have therefore used single-chain fragment variable ( $\mathrm{scFv}$ ) antibodies, which comprise the antigen-binding variable regions of the heavy and light chains of antibodies and retain complete antigen specificity. ScFvs that are specific for every human protein can be relatively easily produced, making these molecules the gold standard for targeting.

Enveloped viruses provide an optimal platform for applying scFvs, as both the ligands and viral envelope glycoproteins are naturally secreted through the same pathway. For example, a recombinant MV that displays an scFv which is specific for the carcinoembryonic antigen was generated and was shown to enter carcinoembryonic-antigen-expressing cells that were not susceptible to entry by wild-type $\mathrm{MV}^{35}$. Subsequently, MV that had been retargeted to bind CD20, a marker for non-Hodgkin's Iymphoma (NHL), and CD38, a marker for myeloma, were also generated using the functional display of scFvs, and were shown to be oncolytic in immunodeficient mice that contained CD20- or CD38-positive cancer xenografts ${ }^{36,37}$. Recently, the oncolytic efficacy of scFv-retargeted MV was demonstrated in an immunocompetent mouse mode ${ }^{38}$.

Proof of principle for a completely retargeted MV was achieved by combining scFvs that were specific for EGF receptor (EGFR) or CD38 displayed on MV haemagglutinin with mutations that ablated productive interactions with the SLAM and CD46 receptors ${ }^{39}$. These retargeted viruses replicated in and killed cancer cells that expressed the targeted receptors, but were unable to infect cells that expressed SLAM or CD46. When administered intratumourally or intravenously to mice with human CD38- or EGFR-positive tumours, these viruses mediated targeted anti-tumour activity. These data provide an in vivo demonstration of antibody-directed tumour destruction by a retargeted oncolytic virus ${ }^{39}$.

ScFv-mediated cell entry through targeted receptors should be applicable to enveloped viruses with glycoproteins that are folded in the same reducing compartment as scFvs, and indeed proof of principle for the applicability of scFvs in retargeting HSV has been achieved ${ }^{40}$. Some success has also been reported for other viruses with capsids that are produced within the cytoplasm, such as Ad, based on the display of $\mathrm{scFvs}^{41}$ and the CD40 ligand ${ }^{42}$. However, these approaches require complex re-engineering or selection of ligands for proper folding and disulphide replacement in this foreign non-reducing environment. In both cases, receptor retargeting holds promise for future generations of clinical oncolytic viruses.

Cancer-specific transcription and replication. Another layer of specificity for cancer cells can be applied at the level of virus replication, by two main approaches. In the first approach, key virus gene products are 


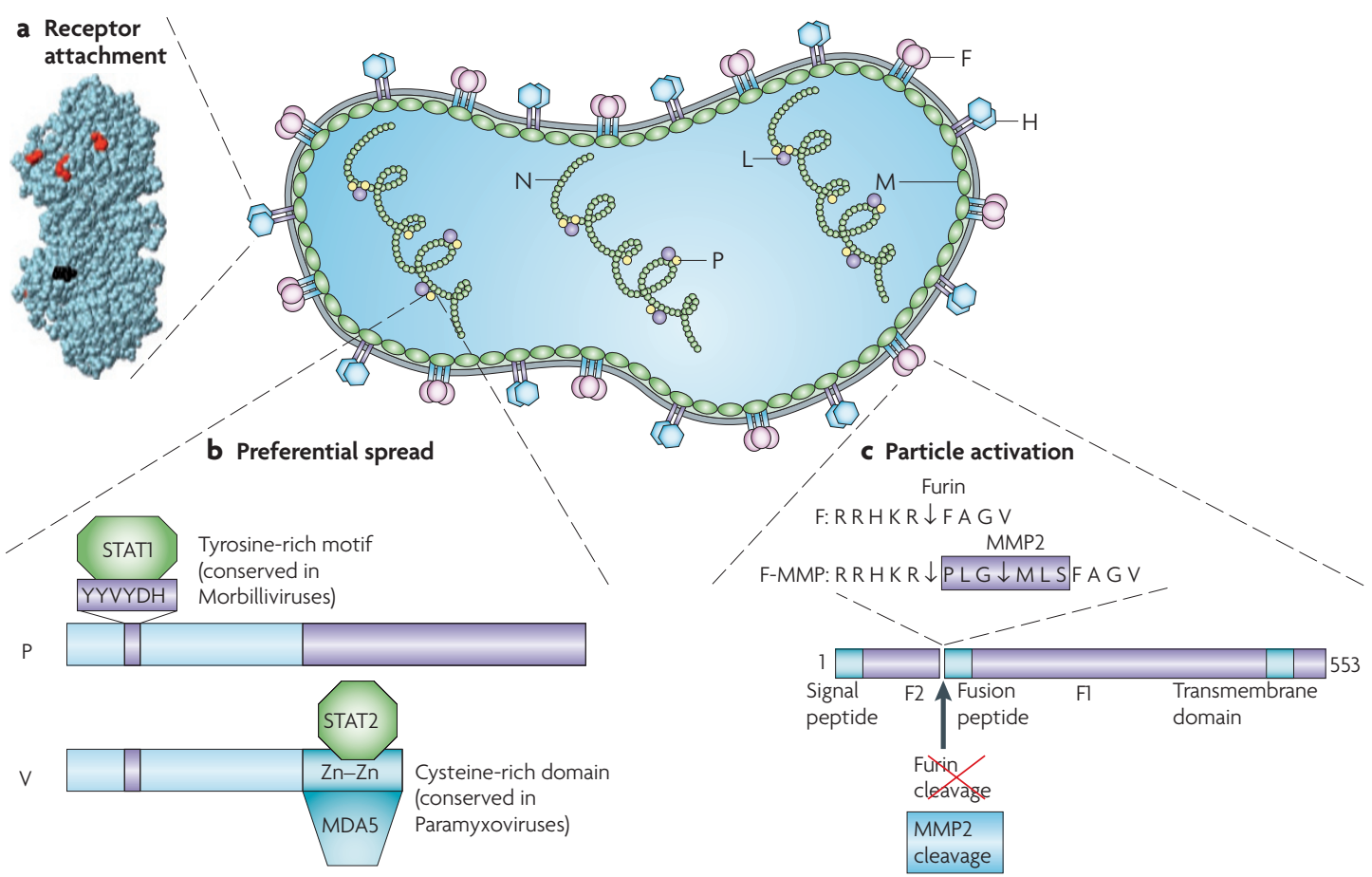

Figure 3 $\mathrm{MV}$ particle structure, genome organization and targeting approaches. The MV genome has six genes that code for eight proteins. The first gene codes for the nucleocapsid protein $(\mathrm{N})$ that encapsidates the genomic RNA. The last gene $(\mathrm{L})$ codes for the polymerase protein that replicates and transcribes the genome together with the phosphoprotein (P), a polymerase cofactor. The matrix protein (M) organizes virus particle assembly. The two glycoproteins haemagglutinin $(\mathrm{H})$ and the fusion $(\mathrm{F})$ protein contact the receptor and execute membrane fusion, respectively. Two non-structural proteins that are coded by the $P$ gene ( $C$ and $\mathrm{V}$ ) control the innate immune response. a | Three-dimensional structure of $\mathrm{MV} \mathrm{H}^{117}$. Residues that are necessary for signalling lymphocytic activation molecule (SLAM)-dependent or CD46-dependent fusion are in red. The site of addition of the single-chain fragment variable (scFv) is in black. $\mathbf{b} \mid \mathrm{A}$ schematic of the $\mathrm{P}$ and $\mathrm{V}$ proteins that are encoded by the $P$ gene. These proteins share their amino-terminal domain, but differ at the carboxyl terminus. The residues of the $\mathrm{V}$ and $\mathrm{P}$ common domain that are important for the interaction with STAT1 (signal transducer and activator of transcription 1) have been characterized. Three amino acids in a conserved hexapeptide are shown in purple. Data from the Horvath group indicate that STAT2 and MDA5 interact with different sequences in the unique cysteine-rich domain of V (A. Ramachandran, J-P. Parisien and C.M. Horvath, unpublished observations). c | Schematic of the MV F protein and amino acid sequences of its cleavage site. The standard $F$ protein is cleaved into $F_{1}$ and $F_{2}$ fragments by furin, a ubiquitous protease. Furin cleavage occurs even after a hexameric peptide that codes for a matrix metalloproteinase 2 (MMP2) cleavage site is introduced (F-MMP), but the resulting $\mathrm{F}_{1}$ protein, which is extended by six residues, is inactive. Trimming of three amino-terminal residues by MMP2 cleavage confers function to F-MMP.

Non-Hodgkin's lymphoma A diverse group of cancers that arise from lymphocytes and have varying courses, treatments and prognoses

Myeloma

A type of cancer of the plasma cells (immune-system cells in bone marrow that produce antibodies) that is often called multiple myeloma. placed under the transcriptional control of tissuespecific or cancer-specific promoters, such that they are preferentially, if not exclusively, expressed in tumour cells. Reprogramming replication functions using such approaches tends to be simpler in DNA viruses, such as Ad, herpesviruses or poxviruses, as these viruses have large genomes and genome-packaging capacities, which facilitates the insertion of exogenous elements. The expression or interactions of the proteins that are encoded by the key Ad early genes $E 1 A, E 1 B$ and $E 4$, for example, has been modified. See REF. 43 for a detailed discussion of the biology of Ad early genes.

In a simplified view, the E1A protein transactivates other Ad promoters that are involved in the virus life cycle (FIG. 4a). E1A also drives cells into synthesis (S) phase to facilitate virus replication and interacts with more than ten proteins, including the retinoblastoma tumour suppressor $(\mathrm{Rb})$ and $\mathrm{p} 300$. The E1B $55 \mathrm{kDa}$ protein $(\mathrm{E} 1 \mathrm{~B}-55 \mathrm{~K})$ binds and destroys the tumour suppressor $\mathrm{p} 53$ to allow entry into $\mathrm{S}$ phase. The E1B 19 $\mathrm{kDa}$ protein prevents the cell from undergoing apoptosis and aborting virus replication. Manipulation of these proteins or their expression can restrict virus replication to targeted cancer cells.

A second approach to cancer-specific replication is to place the E1 or E4 genes under the control of tissuespecific or cancer-cell-specific promoters. For example, expression of $E 1 A$ from the prostate-specific antigen promoter renders Ad replication and cell killing prostate specific (TABLE 1). For prostate cancer, conventional therapy often includes prostate ablation, which allows selection of a tissue-specific, rather than a cancer-specific, promoter $^{44}$. Additionally, the telomerase promoter has been placed upstream of the $E 1$ and/or $E 4$ genes to drive oncolytic virus activity ${ }^{45,46}$. This promoter is an example of the burgeoning number of promoters that are being tested to reprogramme the replication of Ad and other viruses for oncolysis. 


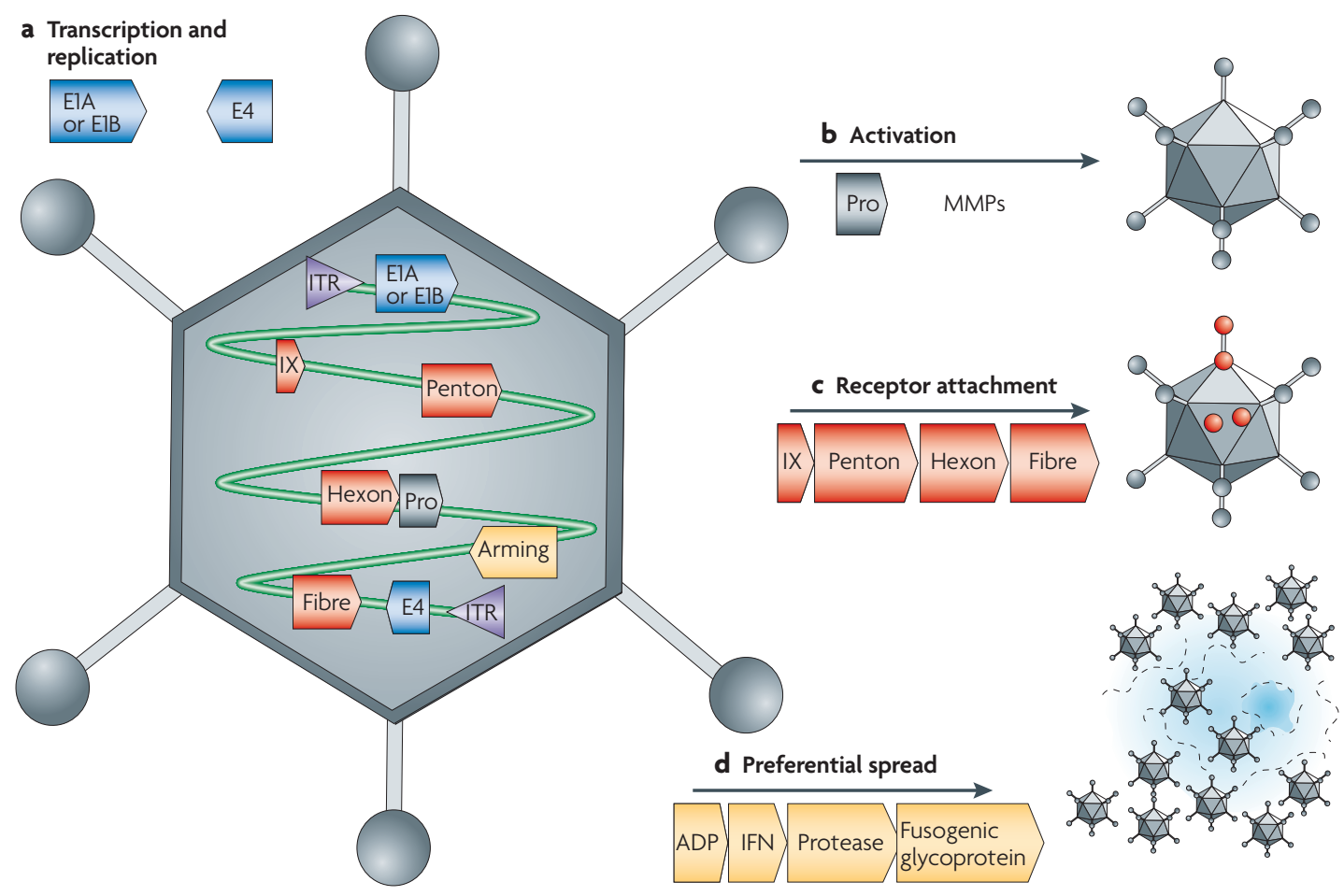

Figure 4 | Adenovirus particle structure, genome organization and targeting approaches. An icosahedral, non-enveloped adenovirus (Ad) particle is shown. The key genes in the viral genome that are relevant to the four targeting approaches discussed in the main text are indicated. a |Cancer-specific transcription and replication targeting are applied to the E1 and E4 genes. $\mathbf{b} \mid$ Cancer-specific proteolytic activation has not yet been attempted. $\mathbf{c} \mid$ Cancer-specific receptor attachment is mediated by genetic or chemical modification of the IX, penton, hexon or fibre proteins or genes. d | Preferential spread targeting can be based on over-expression of the ADP gene and the insertion of exogenous genes into the viral genome. ITR, inverted terminal repeat; MMP, matrix metalloproteinase; Pro, protease.

An interesting example of a virus with cancer specificity of disputed origin is ONYX-015, the archetypical attempt to generate cancer-specific oncolytic Ad. ONYX-015 is derived from the mutant Ad strain d11520, in which E1B-55K is deleted ${ }^{47}$. It was originally thought that the deletion of E1B-55K would protect normal cells from infection by ONYX-015, as these cells express the tumour suppressor p53. By contrast, it was proposed that ONYX-015 would proliferate and kill cancer cells that lack p53 with no restraints. Although early work seemed to support this hypothesis ${ }^{48}$, later studies revealed that the situation is more complex, as ONYX-015 was cytopathic even in the presence of p53 (REF. 49). Tumour selectivity of ONYX-015 is currently mainly attributed to late mRNA export ${ }^{50,51}$. H101, an E1B-55K-deleted virus that is similar to ONYX-015, has recently been approved by the Chinese State Food and Drug Administration for use in combination with chemotherapy in the treatment of late-stage refractory nasopharyngeal cancer (TABLE 1). Approval of H101 or a related product by the United States Food and Drug Administration will be contingent on the availability of extensive survival and quality-of-life data. H101, like ONYX-015, is an important case study in applied virology and the only approved drug in the $\operatorname{clinic}^{18}$, but has only modest cancer selectivity. Both H101 and ONYX-015 also illustrate the need to better integrate observations in different experimental systems and ensure the cancer specificity of oncolytic viruses by applying overlapping layers of cancer specificity.

Exploiting cancer cell defects to balance attenuation. The most potent oncolytic viruses are arguably wild-type viruses. However, these viruses can kill normal cells and cause dose-limiting toxicities. Efforts have therefore been made to reduce the toxicity of most oncolytic viruses by attenuation $^{52}$. For example, in a recent clinical trial that tested the use of herpesvirus in glioma, attenuation of the virus by inactivation of ICP34.5, a neurovirulence gene, and ICP6, the gene that encodes the large subunit of ribonucleotide reductase, made it safe (TABLE 1). As it is possible that this attenuation also reduces oncolytic efficacy ${ }^{53}$, selective expression of ICP34.5 through glioma-specific promoters is being developed ${ }^{54,55}$.

Attenuation is always relative to the target cell. Ideally, oncolytic viruses should be highly attenuated in normal cells, but maintain normal replication in cancer cells. Many viruses replicate well in those cancer cells that have accumulated defects in innate immunity functions, which should allow the viral proteins that are normally used to circumvent these protective measures to be modified without extensively sacrificing replication competence in tumour ${ }^{56}$. However, it is clear that completely ablating the expression of certain virus proteins attenuates viral replication, even in cancer cells, as these virus proteins 


\section{Box 1 | Biochemical versus genetic modification of viruses}

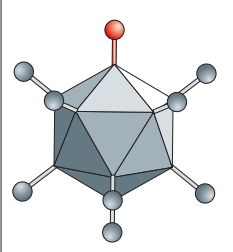

b

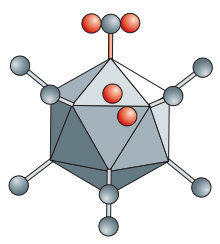

C

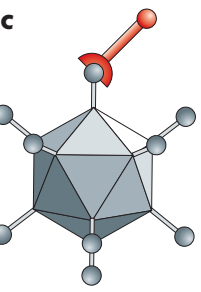

d

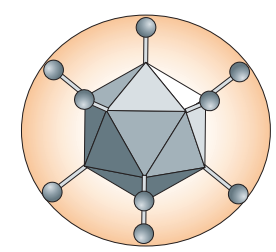

Reprogramming oncolytic viruses requires at least two steps: first, retargeting by adding new ligands to mediate binding to receptors that are expressed on cancer cells, and second, detargeting by blocking promiscuous binding to non-cancer cells. In genetic retargeting, an exogenous ligand is fused to, or replaces, the normal receptorbinding protein of the virus (see the figure, parts $\mathbf{a}$ and $\mathbf{b}$ ). This genetic approach has the advantage that the injected virus and its progeny that are produced during oncolysis will all be targeted. However, genetically retargeting viruses is a complex, technically challenging process. As an alternative, viral particles can be modified chemically (see the figure, parts $\mathbf{c}$ and $\mathbf{d}$ ): they can be conjugated to cell-targeting ligands by using antibody-virus interactions (for example, bi-specific antibodies), molecular bridges (for example, biotin-avidin) or frank covalent coupling with chemical cross-linkers (for example, bifunctional polyethylene glycol (PEG)). As these simple complexing approaches are combinatorial, they can target more than one receptor and avoid the functional complications of introducing foreign domains into viral proteins. However, these approaches only mediate targeting of the inoculated virus. Once progeny virions are produced in the tumour, they default to their genetically encoded tropism. This loss of targeting in progeny and the need to combine multiple Good Manufacturing Practice (GMP)-grade reagents for use in patients makes the biochemical approach more difficult for clinical translation than having one genetically targeted reagent.

Biochemical and genetic targeting are complementary and can be combined. For example, chemical modification could target tumour vasculature, allowing the genetically encoded virus tropism to target cancer cells. In addition, targeting can be performed using polymers such as PEG to 'shield' the virus from antibodies and other interactions (see the figure, part d). Therefore, both chemical and genetic engineering hold promise for targeting oncolytic viruses.

often have multiple functions. Therefore, current attenuation strategies are moving towards conservative modification of virus proteins, through the mutation of single residues that are essential for specific interactions.

For example, many cancerous cells cannot produce interferon (IFN) or respond to IFN stimulation ${ }^{57-61}$. Such abnormalities make these cells highly susceptible to virus infection, and indeed it has been shown that VSV with mutations in the matrix protein, which is responsible for modulating the cellular IFN response, replicates preferentially in these cancer cells ${ }^{62}$. When this study was published, the mechanism by which the mutation operated was not completely understood, but current studies can profit from the identification of the cellular proteins that directly interact with certain virus proteins and, sometimes, from the knowledge of the structural basis of these interactions.

For example, the mechanisms that MV uses to control the IFN system are understood in some detail. IFN binds to neighbouring cells to activate cytoplasmic STAT (signal transducer and activator of transcription) proteins by phosphorylation. Activated STAT proteins function as transcription factors to upregulate the expression of antiviral proteins, thereby protecting the cell in advance of infection ${ }^{63-66}$. Viruses have evolved diverse mechanisms to block the IFN pathway at various points ${ }^{67,68}$. The innate immune defences of cells that are infected with wildtype MV are compromised by expression of the virus non-structural $\mathrm{C}$ and $\mathrm{V}$ proteins, which abrogate IFN signalling by inhibiting STAT phosphorylation ${ }^{69}$ and its translocation to the nucleus ${ }^{70,71}$.

In the first-generation oncolytic MVs that are currently being tested in clinical trials, the $\mathrm{V}$ protein carries a mutation that renders it non-functional, making the viruses highly susceptible to IFN ${ }^{72}$. Importantly, several human ovarian carcinoma cells have been shown to be capable of inducing IFN and controlling the replication of these viruses, thereby limiting their oncolytic efficacy. To increase oncolysis, IFN susceptibility was reversed by replacing the mutated gene with the wild-type sequence ${ }^{73}$. However, increasing oncolysis by including a wild-type gene in an oncolytic virus might enhance its ability to replicate in non-target cells, which raises a potential safety concern.

Identification and characterization at the amino acid level of specific protein interactions, such as between the MV V protein and the IFN machinery, is therefore important. For MV, it is now known that tyrosine 110 and a few neighbouring amino acids in the $\mathrm{N}$ terminus of the phosphoprotein (P) (FIG. 3) are necessary for the interaction with STAT1 (REFS 72,74). It is also known that the cysteine-rich domain of the $\mathrm{V}$ protein interacts directly with the helicase MDA5, thereby limiting the cellular recognition of viral RNA and IFN induction ${ }^{75}$ (FIG. 3). The residues of the $\mathrm{V}$ protein that are involved in this interaction are currently being mapped, together with other $\mathrm{V}$ residues that are important for the interaction with STAT2 (A. Ramachandran, J.P. Parisien and C.M. Horvath, personal communication).

Analogous to the first-generation oncolytic MVs, the oncolytic Ads ONYX-015 and H101 have some level of cancer-cell specificity owing to deletion of the $E 1 B-55 K$ gene, but both are attenuated in normal cells and cancer cells, which limits their effectiveness in the absence of combined therapy (for example, chemotherapy ${ }^{18}$ ). Retargeting the specificity of oncolytic Ad has therefore focused on introducing specific mutations or deletions in E1A to block its binding to Rb and/or p300; this would inhibit virus replication in normal cells, but would allow proliferation and killing in cancer cells without Rb function or with mutations in cell-cycle components ${ }^{76,77}$. These viruses maintain good potency against a range of tumours and have improved safety in animal models. Furthermore, combinations of E1A and E1B mutations have generated a novel Ad that seems to be more cancer-cell-specific than the single-mutant viruses ${ }^{44}$.

In summary, knowledge of the specific interactions between viral and cellular proteins lays the foundations to ablate individual replicative functions of oncolytic viruses (including immune evasion and inhibition of apoptosis) and attenuate replication in normal, but not in certain cancerous, cells. This balanced attenuation will generate oncolytic viruses that are specific for the unique IFN and/or cell-cycle deficiencies of a given cancer type and, eventually, for the tumours of individual patients with cancer. 


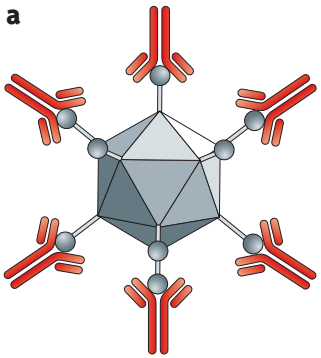
by antibodies
Virus neutralized

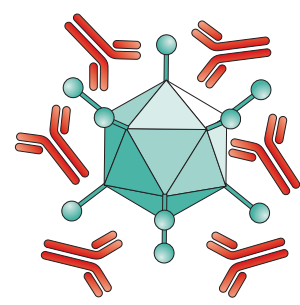

Use different virus serotype

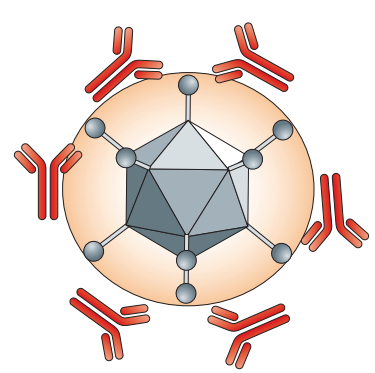

Virus shielded with polymers b

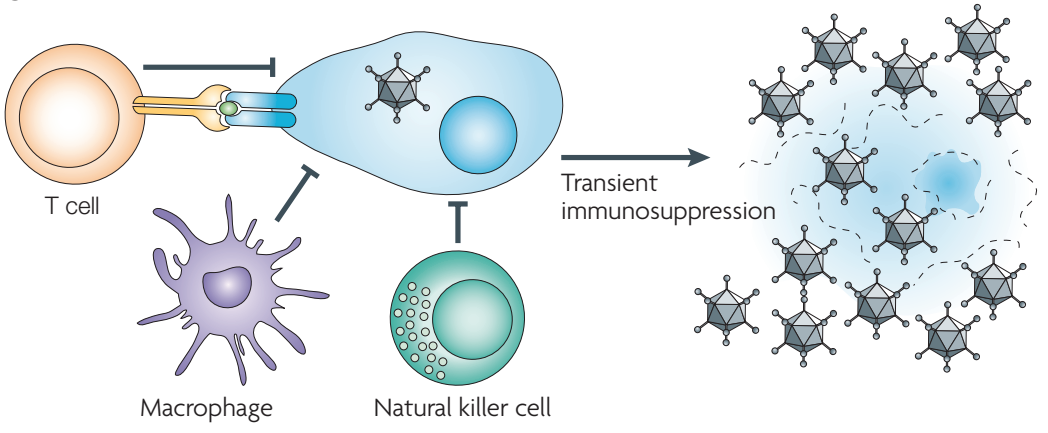

Figure 5 | Strategies to improve oncolytic virus efficacy. a Shielding the virus against antibodies. Pre-existing neutralizing antibodies in humans can interfere with efficacy. Changing virus serotypes and coating particles with shielding polymers can address the neutralizing-antibody problem. $\mathbf{b} \mid$ Transient immunosuppression of the host. Infected cells can be attacked by macrophages, T cells and natural killer cells. Transient immunosuppression interferes with the activation and ability of these cells to recognize and/or kill infected cells and restrict oncolytic efficacy.

\section{Arming viruses}

Arming oncolytic viruses that are inefficient in pre-clinical models or clinical trials with genes that encode prodrug convertases or therapeutic proteins can enhance their potency. This approach is particularly interesting when it is combined with other therapeutic modalities (discussed below). One intrinsic limitation of certain oncolytic approaches is that therapeutic gene delivery is limited to infected cells. If the effect of the encoded protein is cell autonomous (for example, a tumour suppressor protein such as p53), arming will only kill the primary infected cell. By contrast, if the protein is secreted, for example, a cytokine, it can have systemic efficacy, but also side effects. Other proteins, such as thymidine kinase (TK), can have bystander effects that kill neighbouring cells without acting systemically. Immunostimulatory arming proteins, including cancer antigens and cytokines, can also have systemic effects by activating immune responses against cancer cells. It is also possible that cell-autonomous cell-killing genes prime the immune system by generating apoptotic or necrotic cancer cell remnants that can be taken up by antigen-presenting cells for cross-presentation and activation of $\mathrm{T}$ cells against cancer cells.

Prodrug convertase transgenes. Prodrug convertases are enzymes that metabolize non-toxic substrates and convert them into lethal drugs that can act within the infected cell, locally or, in some cases, systemically. Early examples include the use of HSV TK to sensitize cells to the drug ganciclovir ${ }^{78,79}$. This approach adds tumour specificity, as only cells that are dividing (such as cancer cells) are killed by the TK-activated drug. Similar approaches have used other convertases, such as cytosine deaminase ${ }^{80}$, or have combined two convertases into one protein, such as the TK-cytosine deaminase hybrid protein ${ }^{81}$, to apply different layers of cancer specificity and tumour killing.

Pro-apoptotic transgenes. Arming oncolytic viruses with transgenes that are capable of inducing apoptosis is an attractive strategy for improving anti-cancer activity. In combination with replicative viruses, however, apoptosis is a double-edged sword. Premature apoptosis of infected cells can reduce virus progeny yields, thereby counteracting the oncolytic activity of the virus. By contrast, apoptosis that is induced at late stages of virus infection, when the progeny virions are matured, can improve virus release from infected cells ${ }^{82}$ and enhance progeny spread and anti-cancer efficacy. Oncolytic Ads that are engineered to express TRAIL (tumour-necrosis-factorrelated apoptosis-inducing ligand) are more oncolytic than the parental viruses in cancer cell lines and in animal tumour models ${ }^{83-85}$. Arming oncolytic Ads with another pro-apoptotic transgene, $\mathrm{p} 53$, resulted in increased apoptosis in vitro, but not in increased anti-tumour activity in $v i v o^{86,87}$. Therefore, thorough analysis of the expression levels of pro-apoptotic transgenes and the sensitivity to apoptosis of target cancer cells is required to sustain synergistic interactions between the induction of apoptosis and virus-replication-mediated oncolysis.

Immuno-activating transgenes. A complementary approach is to disarm Ad in normal cells by expressing gene products that can further protect normal cells from the leaky toxicity of standard oncolytic Ad. Examples include the delivery of type I or II IFNs or cytokines such as granulocyte-macrophage colony-stimulating factor ${ }^{88}$. A more recent application arms an Ad in cancer cells and disarms it in normal cells. In this case, a KD3 Ad that was targeted by mutations in $E 1 A$ was armed by ADP overexpression. When this KD3 virus was disarmed by expressing an IFN- $\alpha$ gene, its anti-tumour activity was higher than that of the parental virus ${ }^{14}$. IFN expression also suppressed virus replication in normal cells, but not cancer cells. When tested in vivo, the disarmed $\mathrm{KD} 3$ virus mediated better tumour killing and drastically reduced liver toxicity. Although IFN expression disarmed Ad that innately resisted IFN, it should be noted that this strategy cannot be applied to viruses that are highly susceptible to IFN expression. This selective arming approach provides proof of principle for similar modifications in Ad and other viruses, provided that they can propagate genomes with multiple gene additions.

\section{Shielding oncolytic viruses}

Therapy of metastatic disease in patients with intact immunity ${ }^{89}$ will remain a challenge, even for effectively reprogrammed oncolytic viruses. This fact can be 
under-appreciated when viruses are initially tested against human tumours that are grown in immunodeficient mice. Conversely, testing in an immunocompetent animal model has its own caveats, as animal cell tumours might not recapitulate the biology of their human counterparts. Increased therapeutic applicability would be possible with strategies that help viruses and host immunity co-exist or even interact synergistically.

Temporary immunosuppression. Given that many oncolytic viruses are derived from human viruses, the presence of pre-existing neutralizing antibodies in patients with cancer can rapidly inactivate incoming viruses after injection. Even when no antibodies are present, the first injection of an oncolytic virus will induce neutralizing antibodies that can quench the activity of subsequent injections (FIG. 5). Moreover, the innate and cellular immune responses will combat oncolytic viruses. Although this might contribute to the killing of infected cancer cells, it might also lead to the lysis of normal cells in which the virus is replicating. These cellular responses might also reduce the amount of virus that is produced by infected cells and limit virus spread to adjacent tumour cells.

One strategy to limit the effects of neutralizing antibodies is to develop virotherapy protocols for individuals with low levels of antibodies; for example, patients with multiple myeloma ${ }^{90}$. An alternative strategy uses the immunosuppressive side effects of chemotherapeutics such as cyclophosphamide (CPA) to increase oncolysis through combination therapy ${ }^{91}$. CPA is a prodrug that is activated in the liver to a potent DNA-alkylating agent. In addition to its use as a chemotherapeutic for some cancers, CPA is also immunosuppressive, and has therefore been used with several viruses to downregulate immune cells in the brain and facilitate oncolytic spread within tumours ${ }^{92}$. A more recent approach has used the immunosuppressive agent rapamycin to augment oncolytic activity. During organ transplants, rapamycin can bind FK-binding protein 12 to inactivate the mTOR pathway, thereby blocking lymphocyte activation. When applied with the oncolytic poxvirus myxoma virus, rapamycin enabled the virus to infect and kill cancer cells that were normally refractory to virus activity and increased the oncolytic potency in vivo in immunocompetent animals ${ }^{93,94}$. It is important to note that, if complete and prolonged, immunosuppression can allow for some proliferation of the injected cancer cells ${ }^{95}$. Thus, the use of reprogrammed viruses with many different levels of targeting and replication controls reduces certain risks of complete and prolonged immunosuppression, but not all of them.

Biological and chemical shields. One approach to evade neutralizing antibodies is to change the capsid and therefore switch the serotype of the virus. For example, mice that are administered with Ad2 serotype vectors generate potent neutralizing antibodies against Ad2 that drastically reduce transgene expression after subsequent $\mathrm{Ad} 2$ administrations ${ }^{96}$. However, if an $\mathrm{Ad} 2$ vector is used for the first round of transduction and then an Ad5 vector is used for the second round, there is little reduction in transduction, because the Ad2specific antibodies do not overtly neutralize the Ad5 serotype ${ }^{96}$. Similarly, in baboons, serotype switching between Ad2 and Ad5 vectors allowed repeat administration in the presence of neutralizing antibodies that were generated against the first vector ${ }^{97}$. More recent efforts have recruited Ads from uncommon human serotypes or from other species to evade pre-existing and vector-induced antibody and T-cell responses ${ }^{98,99}$. This 'sheep in wolf's clothing' approach will evade preexisting antibodies in humans, but each new vector will generate its own neutralizing antibodies, necessitating the use of additional serotypes for later injections.

Analogously, the serotype of enveloped viruses has been switched. In an effort to develop an effective AIDS vaccine based on live-attenuated VSV, boosting was accomplished using vectors that expressed glycoproteins from different VSV serotypes ${ }^{100}$. MV is a monotypic virus without serotypes, but it has been shown that the envelope glycoproteins of MV and the related morbillivirus canine distemper virus ( $\underline{\mathrm{CDV}})$ can be exchanged to produce chimeric viruses that evade pre-existing immunity ${ }^{101}$ (J. Lampe, G. Ungerechts and R.C., unpublished observations).

An alternative approach is to chemically shield viruses with polymers such as polyethylene glycol (PEG) or poly-(N-(2-hydroxypropyl)methacrylamide) (pHPMA). These hydrophilic polymers can be chemically cross-linked to viruses to shield them from preexisting antibody responses and reduce new antibody and T-cell responses ${ }^{102-107}$ (BOX 1). Although polymer coating can markedly reduce virus infection, at least for Ad, this is largely an in vitro effect that is not always replicated in $v i v o^{104}$. Indeed, shielding can, in some cases, enhance tumour infection by reducing virus uptake into normal tissues ${ }^{108}$. Chemical crosslinking of polymers to icosahedral capsids is a wellestablished technique, but how tractable different enveloped viruses will be to polymer coating remains to be determined.

An additional prospect for shielding viruses is the use of ex vivo infected cells as carriers for oncolytic viruses. The original delivery paradigm, which was based on the injection of virus directly into the bloodstream, has not yet efficiently confronted issues such as the natural tendency of viruses to traffic to the liver, spleen and lung. Success has been demonstrated with various cell types, including mesenchymal cells, T cells and monocytes ${ }^{109,110}$. Recent work has focused on myeloma cells as carriers for oncolytic VSV in the therapy of multiple myeloma, a disseminated malignancy that is marked by defined trafficking of malignant plasma cells. Myeloma cells were capable of delivering replication-competent VSV to sites of malignancy after supra-lethal doses of ionizing radiation in an orthotopic mouse model ${ }^{110}$. Cell carriers have the potential to increase the efficiency of oncolytic virotherapy by shielding the virus from the immune system and actively trafficking the virus to the sites of malignancy. 


\section{Box 2 | Five steps for reprogramming viruses into cancer therapeutics}

\section{Know the virus}

Characterize the tropism determinants of the virus of interest, if possible at the amino acid level. Detailed knowledge of as many relevant interactions between viral and cellular proteins as possible is the most important prerequisite for successful reprogramming.

\section{Know the cancer}

Virologists should be aware of the most promising cancers for possible treatment with oncolytic vectors. Preferred cancers include malignancies that are derived from cell types in which the parental virus spreads efficiently.

\section{Move rapidly to pre-clinical models}

Viruses kill cultivated cells efficiently, but the reduction of tumours in mice is a better test for efficacy. Keep focused on the final goal, work with reporter or tracker genes and define objective parameters of safety and efficacy.

\section{Combine reprogramming principles}

Work on different layers of targeting individually, and then combine them. Characterize how your targeted oncolytic virus can be shielded from the immune system. Arm it with a prodrug convertase that synergizes with a chemotherapeutic that is in clinical use and document the efficacy of different therapeutic regimens.

In the end, only efficacy and safety in humans count

To have experimental correlates of human efficacy would be wonderful, but without good animal models we are always guessing. Translate promising therapeutics from bench to bedside in a timely manner. nucleotide phosphorylase, which converts fludarabine phosphate to a highly diffusible substance that is capable of efficiently killing bystander cells. The CD20targeted and convertase-armed MV was shown to synergize with fludarabine and to be effective after systemic inoculation in a mantle cell lymphoma xenograft model ${ }^{114}$. The next logical step is to synchronize vector delivery with CPA administration to open a broader window of therapeutic opportunity. Thus, studies that are based on the combination of oncolytic viruses with proven therapeutics could facilitate the integration of these vectors into current cancer regimens.

\section{The future: safety and efficacy}

Five steps facilitate the reprogramming of viruses into effective cancer therapeutics. BOX 2 explains how these steps support the translation of promising therapeutics into clinical practice. To serve the needs of the patient with cancer, efficacy and safety go hand in hand. Engineering more effective, immunoevasive viruses must be performed with careful thought to protect not just the patient, but also his or her contacts.

Careful thought must be given to which genes should be engineered into an infectious agent. The introduction of immunosuppressive or immuneskewing genes into replication-competent viruses needs to be weighed most heavily. The insertion of the interleukin-4 gene into the mousepox ectromelia virus provides a cautionary example of what can go wrong ${ }^{115}$ : the virus suppressed the ability of the immune system to kill infected cells and blocked the production of memory immune responses, thereby enhancing virulence. The consequences of engineering a virus that harms the patient or spreads to other individuals are obvious and unacceptable.

Alternative approaches to safeguard the replication of oncolytic viruses include transient immunosuppression, which can be withdrawn if problems arise, or drug therapies that can specifically and transiently block virus-specific immune responses, such as monoclonal antibodies that target specific cells or immune proteins. Using replication-defective viruses that express potent transgenes to complement replicationcompetent, but less virulent, oncolytic viruses might also be safe and efficient ${ }^{116}$. Another important area of research is the development of oncolytic viruses with life cycles that can be terminated by a prodrug ${ }^{114}$.

In summary, oncolytic viruses hold great promise as potent, self-amplifying cancer therapeutics. Virotherapy is attractive because there is no crossresistance with chemotherapy and radiation therapies. Ad H101 is the first reprogrammed virus to be approved as a cancer drug; it has been administered to hundreds of patients with head and neck carcinoma in China, in combination with chemotherapy, and survival statistics and clinical-benefit data might support the worldwide usage of this virus. In the next few years, oncolytic viruses with increasingly sophisticated targeting combinations should become available for clinical trials. The future is getting brighter for patients with cancer. 
1. Dock, G. The influence of complicating diseases upon leukemia. Am. J. Med. Sci. 127, 563-592 (1904).

2. Sinkovics, J. \& Horvath, J. New developments in the virus therapy of cancer: a historical review. Intervirology 36, 193-214 (1993).

3. Kelly, E. \& Russell, S. J. History of oncolytic viruses: genesis to genetic engineering. Mol. Ther. 15, 651-659 (2007)

A compelling narrative of the first 100 years of oncolytic viruses.

4. Hoster, H., Zanes, R. \& Vonhaam, E. The association of "viral" hepatitis and Hodgkin's disease. Cancer Res. 9, 473-480 (1949).

5. Moore, A. E. Viruses with oncolytic properties and their adaptation to tumors. Ann. NY Acad. Sci. 54 945-952 (1952).

6. Southam, C. M. $£$ Moore, A. E. Clinical studies of viruses as antineoplastic agents with particular reference to Egypt 101 virus. Cancer 5, 1025-1034 (1952).

7. Newman, W. \& Southam, C. M. Virus treatment in advanced cancer: a pathological study of fifty-seven cases. Cancer 7, 106-118 (1953).

A clinical study that seems alarming in the context of current ethical standards.

8. Huebner, R. J., Rowe, W. P., Schatten, W. E., Smith, R. R. \& Thomas, L. B. Studies on the use of viruses in the treatment of carcinoma of the cervix. Cancer $\mathbf{9}$, 1211-1218 (1956).

9. Suskind, R. G., Huebner, R. J., Rowe, W. P. \& Love, R. Viral agents oncolytic for human tumors in heterologous host; oncolytic effect of Coxsackie B viruses. Proc. Soc. Exp. Biol. Med. 94, 309-318 (1957).

10. Pond, A. R. \& Manuelidis, E. E. Oncolytic effect of poliomyelitis virus on human epidermoid carcinoma (hela tumor) heterologously transplanted to guinea pigs. Am. J. Pathol. 45, 233-249 (1964).

11. Hammon, W. M., Yohn, D. S., Casto, B. C. \& Atchison, R. W. Oncolytic potentials of nonhuman viruses for human cancer. J. Natl Cancer Inst. 31, 329-345 (1963).

12. Molomut, N. \& Padnos, M. Inhibition of transplantable and spontaneous murine tumours by the M-P virus. Nature 208, 948-950 (1965).

13. Yohn, D. S., Hammon, W. M., Atchison, R. W. $\delta$ Casto, B. C. Oncolytic potentials of nonhuman viruses for human cancer. II. Effects of five viruses on heterotransplantable human tumors. J. Natl Cancer Inst. 41, 523-529 (1968)

14. Shashkova, E. V., Spencer, J. F., Wold, W. S. \& Doronin, K. Targeting interferon- $\alpha$ increases antitumo efficacy and reduces hepatotoxicity of E1A-mutated spread-enhanced oncolytic adenovirus. Mol. Ther. 15 598-607 (2007)

15. Doyle, T. C., Burns, S. M. \& Contag, C. H. In vivo bioluminescence imaging for integrated studies of infection. Cell. Microbiol. 6, 303-317 (2004).

16. Piwnica-Worms, D., Schuster, D. P. \& Garbow, J. R. Molecular imaging of host-pathogen interactions in intact small animals. Cell. Microbiol. 6, 319-331 (2004).

17. Peng, K. W. et al. Pharmacokinetics of oncolytic measles virotherapy: eventual equilibrium between virus and tumor in an ovarian cancer xenograft model. Cancer Gene Ther. 13, 732-738 (2006).

18. Liu, T. C., Galanis, E. \& Kirn, D. Clinical trial results with oncolytic virotherapy: a century of promise, a decade of progress. Nature Clin. Pract. Oncol. 4, 101-117 (2007) A current review of clinical trials of oncolytic viruses.

19. Klenk, H. D. \& Garten, W. Host cell proteases controlling virus pathogenicity. Trends Microbiol. 2, 39-43 (1994)

20. Egeblad, M. \& Werb, Z. New functions for the matrix metalloproteinases in cancer progression. Nature Rev Cancer 2, 161-174 (2002).

21. Morling, F. J., Peng, K. W., Cosset, F. L. \& Russell, S. J. Masking of retroviral envelope functions by oligomerizing polypeptide adaptors. Virology 234 , 51-61 (1997)

22 Peng, K. W., Vile, R., Cosset, F. L. \& Russell, S Selective transduction of protease-rich tumors by matrix-metalloproteinase-targeted retroviral vectors. Gene Ther. 6, 1552-1557 (1999).

23. Kinoh, H. et al. Generation of a recombinant Sendai virus that is selectively activated and lyses human tumor cells expressing matrix metalloproteinases. Gene Ther. 11, 1137-1145 (2004).
24. Springfeld, C. et al. Oncolytic efficacy and enhanced safety of measles virus activated by tumor-secreted matrix metalloproteinases. Cancer Res. 66 7694-7700 (2006)

Demonstration of both the efficacy and safety of tumour protease-activated viruses.

25. Andreasaen, P. A., Egelund, R. \& Petersen, H. H. The plasminogen activation system in tumor growth invasion, and metastasis. Cell. Mol. Life Sci. 57 25-40 (2000).

26. Waehler, R., Russell, S. J. \& Curiel, D. T. Engineering targeted viral vectors for gene therapy. Nature Rev. Genet. 8, 573-587 (2007)

27. Campos, S. K. \& Barry, M. A. Current advances and future challenges in adenoviral vector biology and targeting. Curr. Gene Ther. 7, 189-204 (2007).

28. Navaratnarajah, C. K., Leonard, V. H. L. \& Cattaneo, R. in Measles Virus (Springer, Heidelberg, in the press).

29. Lamb, R. A., Paterson, R. G. \& Jardetzky, T. S Paramyxovirus membrane fusion: lessons from the $\mathrm{F}$ and $\mathrm{HN}$ atomic structures. Virology 344, 30-37 (2006)

30. Tatsuo, H., Ono, N., Tanaka, K. \& Yanagi, Y. SLAM (CDw150) is a cellular receptor for measles virus. Nature 406, 893-897 (2000).

31. Dorig, R. E., Marcil, A., Chopra, A. \& Richardson, C. D. The human CD46 molecule is a receptor for measles virus (Edmonston strain). Cell 75, 295-305 (1993).

32. Naniche, D. et al. Human membrane cofactor protein (CD46) acts as a cellular receptor for measles virus. J. Virol. 67, 6025-6032 (1993).

33. Vongpunsawad, S., Oezgun, N., Braun, W. \& Cattaneo, R. Selectively receptor-blind measles viruses: identification of residues necessary for SLAMor CD46-induced fusion and their localization on a new hemagglutinin structural model. J. Virol. 78, 302-313 (2004).

Proof of principle for the concept of generating selectively receptor-blind viruses.

34. Schneider, U., Bullough, F., Vongpunsawad, S Russell, S. J. \& Cattaneo, R. Recombinant measles viruses efficiently entering cells through targeted receptors. J. Virol. 74, 9928-9936 (2000).

35. Hammond, A. L. et al. Single-chain antibody displayed on a recombinant measles virus confers entry through the tumor-associated carcinoembryonic antigen. J. Virol. 75, 2087-2096 (2001).

36. Bucheit, A. D. et al. An oncolytic measles virus engineered to enter cells through the CD20 antigen. Mol. Ther. 7, 62-72 (2003).

37. Peng, K.-W. et al. Oncolytic measles virus displaying a single chain antibody against CD38, a myeloma cell marker. Blood 101, 2557-2562 (2003).

38. Ungerechts, G et al. An immunocompetent murine model for oncolysis with an armed and targeted measles virus. Mol. Ther. 15, 1991-1997 (2007)

39. Nakamura, T. et al. Rescue and propagation of fully retargeted oncolytic measles viruses. Nature Biotechnol. 23, 209-214 (2005). The first demonstration of oncolytic efficacy after detargeting and retargeting at the receptor-recognition level.

40. Zhou, G. \& Roizman, B. Construction and properties of a herpes simplex virus 1 designed to enter cells solely via the IL- $13 \propto 2$ receptor. Proc. Natl Acad. Sci. USA 103, 5508-5513 (2006).

41. Hedley, S. J. et al. An adenovirus vector with chimeric fiber incorporating stabilized single chain antibody achieves targeted gene delivery. Gene Ther 13, 88-94 (2006).

42. Belousova, N. et al. Genetically targeted adenovirus vector directed to CD40-expressing cells. J. Virol. 77 11367-11377 (2003).

43. Berk, A. J. Recent lessons in gene expression, cell cycle control, and cell biology from adenovirus. Oncogene 24, 7673-7685 (2005).

44. Kim, J., Kim, J. H., Choi, K. J., Kim, P. H. \& Yun, C. O. $\mathrm{E} 1 \mathrm{~A}-$ and $\mathrm{E} 1 \mathrm{~B}$-double mutant replicating adenovirus elicits enhanced oncolytic and antitumor effects. Hum. Gene Ther. 18, 773-786 (2007).

45. Kim, E. et al. Ad-mTERT- $\Delta 19$, a conditional replication-competent adenovirus driven by the human telomerase promoter, selectively replicates in and elicits cytopathic effect in a cancer cell-specific manner. Hum. Gene Ther. 14, 1415-1428 (2003)

46. Kuppuswamy, M. et al. Oncolytic adenovirus that overproduces ADP and replicates selectively in tumors due to hTERT promoter-regulated E4 gene expression. Gene Ther. 12, 1607-1617 (2005).
47. Barker, D. D. \& Berk, A. J. Adenovirus proteins from both $\mathrm{E} 1 \mathrm{~B}$ reading frames are required for transformation of rodent cells by viral infection and DNA transfection. Virology 156, 107-121 (1987).

48. Bischoff, J. R. et al. An adenovirus mutant that replicates selectively in p53-deficient human tumor cells. Science 274, 373-376 (1996).

49. Goodrum, F. D. \& Ornelles, D. A. p53 status does not determine outcome of E1B 55-kilodalton mutant adenovirus lytic infection. J. Virol. 72, 9479-9490 (1998).

50. O'Shea, C. C., Soria, C., Bagus, B. \& McCormick, F. Heat shock phenocopies E1B-55K late functions and selectively sensitizes refractory tumor cells to ONYX-015 oncolytic viral therapy. Cancer Cell 8 , 61-74 (2005).

51. O'Shea, C. C. et al. Late viral RNA export, rather than p53 inactivation, determines ONYX-015 tumor selectivity. Cancer Cell 6, 611-623 (2004).

52. Chung, R. Y., Saeki, Y. \& Chiocca, E. A. B-myb promoter retargeting of herpes simplex virus $\gamma 34.5$ gene-mediated virulence toward tumor and cycling cells. J. Virol. 73, 7556-7564 (1999).

53. Markert, J. M. et al. Conditionally replicating herpes simplex virus mutant, G207 for the treatment of malignant glioma: results of a phase I trial. Gene Ther 7, 867-874 (2000)

54. Kanai, R. et al. Enhanced therapeutic efficacy of G207 for the treatment of glioma through Musashi 1 promoter retargeting of $\gamma 34$.5-mediated virulence. Gene Ther. 13, 106-116 (2006)

55. Kambara, H., Okano, H., Chiocca, E. A. \& Saeki, Y. An oncolytic HSV-1 mutant expressing ICP34.5 under control of a nestin promoter increases survival of animals even when symptomatic from a brain tumor. Cancer Res. 65, 2832-2839 (2005).

56. Randall, R. E. ¿ Goodbourn, S. Interferons and viruses: an interplay between induction, signalling, antiviral responses and virus countermeasures. J. Gen. Virol. 89, 1-47 (2008).

A current and complete review of the diverse strategies that are adopted by viruses to control the IFN system.

57. Linge, C., Gewert, D., Rossmann, C., Bishop, J. A. \& Crowe, J. S. Interferon system defects in human malignant melanoma. Cancer Res. 55, 4099-4104 (1995).

58. Matin, S. F. et al. Impaired $\alpha$-interferon signaling in transitional cell carcinoma: lack of p48 expression in 5637 cells. Cancer Res. 61, 2261-2266 (2001).

59. Ralph, S. J. et al. Resistance of melanoma cell lines to interferons correlates with reduction of IFN-induced tyrosine phosphorylation. Induction of the anti-viral state by IFN is prevented by tyrosine kinase inhibitors. J. Immunol. 154, 2248-2256 (1995).

60. Sun, W. H. et al. Interferon- $\alpha$ resistance in a cutaneous T-cell lymphoma cell line is associated with lack of STAT1 expression. Blood 91, 570-576 (1998).

61. Wong, L. H. et al. Interferon-resistant human melanoma cells are deficient in ISGF3 components, STAT1, STAT2, and p48-ISGF3 $\gamma$. J. Biol. Chem. 272 28779-28785 (1997).

62. Stojdl, D. F. et al. VSV strains with defects in their ability to shutdown innate immunity are potent systemic anti-cancer agents. Cancer Cell 4, 263-275 (2003).

63. Aaronson, D. S. \& Horvath, C. M. A road map for those who don't know JAK-STAT. Science 296 1653-1655 (2002).

64. Darnell, J. E. J. STATS and gene regulation. Science 277, 1630-1635 (1997).

65. Samuel, C. E. Antiviral actions of interferons. Clin. Microbiol. Rev. 14, 778-809 (2001)

66. Stark, G. R., Kerr, I. M., Williams, B. R., Silverman, R. H. \& Schreiber, R. D. How cells respond to interferons. Annu. Rev. Biochem. 67, 227-264 (1998)

67. Conzelmann, K. K. Transcriptional activation of $\alpha / \beta$ interferon genes: interference by nonsegmented negative-strand RNA viruses. J. Virol. 79, 5241-5248 (2005).

68. Garcia-Sastre, A. Mechanisms of inhibition of the host interferon $\alpha-\beta$-mediated antiviral responses by viruses. Microbes Infect. 4, 647-655 (2002)

69. Takeuchi, K., Kadota, S. I., Takeda, M., Miyajima, N. \& Nagata, K. Measles virus V protein blocks interferon (IFN) $\alpha / \beta$ but not IFN- $\gamma$ signaling by inhibiting STAT 1 and STAT2 phosphorylation. FEBS Lett. $\mathbf{5 4 5}$ 177-182 (2003)

70. Horvath, C. M. Weapons of STAT destruction. Interferon evasion by paramyxovirus $\mathrm{V}$ protein Eur. J. Biochem. 271, 4621-4628 (2004) 
71. Palosaari, H., Parisien, J. P. Rodriguez, J. J., Ulane, C. M. \& Horvath, C. M. STAT protein interference and suppression of cytokine signal transduction by measles virus $\mathrm{V}$ protein. J. Virol. 77, 7635-7644 (2003).

72. Devaux, P., von Messling, V., Songsungthong, W., Springfeld, C. \& Cattaneo, R. Tyrosine 110 in the measles virus phosphoprotein is required to block STAT 1 phosphorylation. Virology 360, 72-83 (2007).

73. Haralambieva, I. et al. Engineering oncolytic measles virus to circumvent the intracellular innate immune response. Mol. Ther. 15, 588-597 (2007).

74. Ohno, S., Ono, N., Takeda, M., Takeuchi, K. \& Yanagi, Y. Dissection of measles virus V protein in relation to its ability to block alpha/beta interferon signal transduction. J. Gen. Virol. 85, 2991-2999 (2004).

75. Childs, K. et al. mda-5, but not RIG-I, is a common target for paramyxovirus $\mathrm{V}$ proteins. Virology 359 190-200 (2007).

76. Doronin, K. et al. Tumor-specific, replication-competent adenovirus vectors overexpressing the adenovirus death protein. J. Virol. 74, 6147-6155 (2000).

77. Fueyo, J. et al. A mutant oncolytic adenovirus targeting the $\mathrm{Rb}$ pathway produces anti-glioma effect in vivo. Oncogene 19, 2-12 (2000).

78. Boviatsis, E. J. et al. Long-term survival of rats harboring brain neoplasms treated with ganciclovir and a herpes simplex virus vector that retains an intact thymidine kinase gene. Cancer Res. 54 5745-5751 (1994).

79. Chase, M., Chung, R. Y. \& Chiocca, E. A. An oncolytic viral mutant that delivers the CYP2B1 transgene and augments cyclophosphamide chemotherapy. Nature Biotechnol. 16, 444-448 (1998).

80. Searle, P. F. et al. Nitroreductase: a prodrug-activating enzyme for cancer gene therapy. Clin. Exp. Pharmacol. Physiol. 31, 811-816 (2004).

81 Freytag, S. O., Rogulski, K. R., Paielli, D. L., Gilbert, J. D. \& Kim, J. H. A novel three-pronged approach to kill cancer cells selectively: concomitant viral, double suicide gene, and radiotherapy. Hum. Gene Ther. 9, 1323-1333 (1998).

82. Mi, J., Li, Z., Ni, S., Steinwaerder, D. \& Lieber, A Induced apoptosis supports spread of adenovirus vectors in tumors. Hum. Gene Ther. 12, 1343-1352 (2001).

83. Sova, P. et al. A tumor-targeted and conditionally replicating oncolytic adenovirus vector expressing TRAIL for treatment of liver metastases. Mol. Ther 9, 496-509 (2004).

84. Dong, F. et al. Eliminating established tumor in nu/nu nude mice by a TRAIL-armed oncolytic adenovirus. Clin. Cancer Res. 12, 5224-5230 (2006)

85. Ren, X.-W. et al. A tumor-specific conditionally replicative adenovirus vector expressing TRAIL for gene therapy of hepatocellular carcinoma. Cancer Gene Ther. 13, 159-168 (2006).

86. Sauthoff, H. et al. Modification of the p53 transgene of a replication-competent adenovirus prevents mdm2- and E1b-55kD-mediated degradation of p53. Cancer Gene Ther. 13, 686-695 (2006).

87. Idema, S. et al. $\mathrm{Ad} \Delta 24$ and the p53-expressing variant $\mathrm{Ad} \Delta 24$-p53 achieve potent anti-tumor activity in glioma when combined with radiotherapy. J. Gene Med. 9, 1046-1056 (2007)

88. Zhang, J. F. et al. Treatment of a human breast cancer xenograft with an adenovirus vector containing an interferon gene results in rapid regression due to viral oncolysis and gene therapy. Proc. Natl Acad. Sci. USA 93, 4513-4518 (1996)
89. Vile, R., Ando, D. \& Kirn, D. The oncolytic virotherapy treatment platform for cancer: unique biological and biosafety points to consider. Cancer Gene Ther. 9, 1062-1067 (2002)

90. Peng, K. W. et al. Systemic therapy of myeloma xenografts by an attenuated measles virus. Blood 98, 2002-2007 (2001).

91. Ikeda, K. et al. Oncolytic virus therapy of multiple tumors in the brain requires suppression of innate and elicited antiviral responses. Nature Med. 5, 881-887 (1999)

92. Lamfers, M. L. et al. Cyclophosphamide increases transgene expression mediated by an oncolytic adenovirus in glioma-bearing mice monitored by bioluminescence imaging. Mol. Ther. 14, 779-788 (2006)

93. Stanford, M. M., Barrett, J. W., Nazarian, S. H. Werden, S. \& McFadden, G. Oncolytic virotherapy synergism with signaling inhibitors: rapamycin increases myxoma virus tropism for human tumor cells J. Virol. 81, 1251-1260 (2007).

94. Lun, X. Q. et al. Targeting human medulloblastoma: oncolytic virotherapy with myxoma virus is enhanced by rapamycin. Cancer Res. 67, 8818-8827 (2007).

95. Yamauchi, K. et al. Induction of cancer metastasis by cyclophosphamide pretreatment of host mice: an opposite effect of chemotherapy. Cancer Res. 68 , 516-520 (2008).

96. Parks, R., Evelegh, C. \& Graham, F. Use of helperdependent adenoviral vectors of alternative serotypes permits repeat vector administration. Gene Ther. 6 1565-1573 (1999)

97. Morral, N. et al. Administration of helper-dependent adenoviral vectors and sequential delivery of different vector serotype for long-term liver-directed gene transfer in baboons. Proc. Natl Acad. Sci. USA 96, 12816-12821 (1999)

98. Hemminki, A. et al. A canine conditionally replicating adenovirus for evaluating oncolytic virotherapy in a syngeneic animal model. Mol. Ther. 7, 163-173 (2003).

99. Xiang, Z. Q. et al. Oral vaccination of mice with adenoviral vectors is not impaired by preexisting immunity to the vaccine carrier. J. Virol. 77 10780-10789 (2003)

100. Rose, N. F. et al. An effective AIDS vaccine based on live attenuated vesicular stomatitis virus recombinants. Cell 106, 539-549 (2001).

101. von Messling, V., Zimmer, G., Herrler, G., Haas, L. \& Cattaneo, R. The hemagglutinin of canine distemper virus determines tropism and cytopathogenicity. J. Virol. 75, 6418-6427 (2001)

102. Croyle, M. A., Chirmule, N., Zhang, Y. A. \& Wilson, J. M. "Stealth" adenoviruses blunt cell-mediated and humoral immune responses against the virus and allow for significant gene expression upon readministration in the lung. J. Virol. 75, 4792-4801 (2001)

103. Fisher, K. D. et al. Polymer-coated adenovirus permits efficient retargeting and evades neutralizing antibodies. Gene Ther 8, 341-348 (2001).

104. Hofherr, S. E., Mok, H., Gushiken, F. C., Lopez, J. A. \& Barry, M. A. Polyethylene glycol modification of adenovirus reduces platelet activation, endothelial cell activation, and thrombocytopenia. Hum. Gene Ther. 18, 837-848 (2007).

105. Lanciotti, J. et al. Targeting adenoviral vectors using heterofunctional polyethylene glycol FGF2 conjugates. Mol. Ther. 8, 99-107 (2003).

106. Mok, H., Palmer, D. J., Ng, P. \& Barry, M. A. Evaluation of polyethylene glycol modification of firstgeneration and helper-dependent adenoviral vectors to reduce innate immune responses. Mol. Ther. 11, 66-79 (2005).
107. O'Riordan, C. R et al. PEGylation of adenovirus with retention of infectivity and protection from neutralizin antibody in vitro and in vivo. Hum. Gene Ther. 10 1349-1358 (1999).

108. Fisher, K. D. et al. Passive tumor targeting of polymercoated adenovirus for cancer gene therapy. J. Drug Target. 15, 546-551 (2007)

109. Harrington, K. \& Vile, R. Virus smuggling, tax evasion and tumor assassination. Nature Med. 12, 507-509 (2006).

110. Munguia, A., Ota, T., Miest, T. \& Russell, S. J. Cell carriers to deliver oncolytic viruses to sites of myeloma tumor growth. Gene Ther. 15, 797-806 (2008).

111. Khuri, F. R. et al. A controlled trial of intratumoral ONYX-015, a selectively-replicating adenovirus, in combination with cisplatin and 5-fluorouracil in patients with recurrent head and neck cancer. Nature Med. 6, 879-885 (2000).

112. Freytag, S. O. et al. Phase I study of replicationcompetent adenovirus-mediated double-suicide gene therapy in combination with conventional-dose threedimensional conformal readiation therapy for the treatment of newly diagnosed, intermediate- to highrisk prostate cancer. Cancer Res. 63, 7497-7506 (2003).

113. Barton, K. N. et al. Second-generation replication competent oncolytic adenovirus armed with improved suicide genes and ADP gene demonstrates greater efficacy without increased toxicity. Mol. Ther. 13 , 347-356 (2006)

114. Ungerechts, G. et al. Lymphoma chemovirotherapy: CD20-targeted and convertase-armed measles virus can synergize with fludarabine. Cancer Res. 67 10939-10947 (2007).

An example of how oncolytic vectors can be reprogrammed to take advantage of various components of current cancer therapy regimens.

115. Jackson, R. J. et al. Expression of mouse interleukin- 4 by a recombinant ectromelia virus suppresses cytolytic lymphocyte responses and overcomes genetic resistance to mousepox. J. Virol. 75, 1205-1210 (2001).

116. Shashkova, E. V., Kuppuswarmy, M. N., Wold, W. S. \& Doronin, K. Anticancer activity of oncolytic adenovirus vector armed with IFN- $\alpha$ and ADP is enhanced by pharmacologically controlled expression of TRAIL. Cancer Gene Ther. 15, 61-72 (2008).

117. Hashiguchi, T. et al. Crystal structure of measles virus hemagglutinin provides insight into effective vaccines. Proc. Natl Acad. Sci. USA 104, 19535-19540 (2007)

Acknowledgements

R.C. has been supported by the National Institutes of Health (grant CA90636) and the Alliance of Cancer Gene Therapy. M.A.B. has been supported by the Department of Defense (grant W81XWH-05-1-0269) and the Susan G. Komen Foundation (grant BCTR0504036).

\section{DATABASES}

Entrez Genome Project: http://www.ncbi.nlm.nih.gov/ entrez/query.fcgi?db=genomepr CDV $\mid$ HIV-1|HSV1 |MV |NDV

FURTHER INFORMATION

Roberto Cattaneo's homepage: http://mayoresearch.mayo edu/mayo/research/staff/cattaneo_r.cfm Michael A. Barry's homepage: http://mayoresearch.mayo. edu/mayo/research/staff/barry ma.cfm Virology and Gene Therapy Ph.D. Program homepage: http://www.mayo.edu/mgs/vgt.html ALL LINKS ARE ACTIVE IN THE ONLINE PDF 